\title{
Interaction of analytical chemistry with accreditation/certification
}

\author{
Ioannis Papadakis ${ }^{1}$ - Fragoulis D. Krokos ${ }^{1,2} \cdot$ Christos Trapalis $^{3}$
}

Received: 21 February 2016 / Accepted: 4 April 2016/Published online: 4 May 2016

(C) Springer-Verlag Berlin Heidelberg 2016

\section{Introduction}

This paper aims to demonstrate the usefulness of analytical chemistry in relation with quality. Over the past decades, quality was discussed by scientists and various definitions were formulated; however, according to ISO 9000 (International Organization for Standardization 2015c) quality is defined as "degree to which a set of inherent characteristics of an entity, such as product, service, process, person, organization, system, resource, fulfills requirements." By the broadness of this definition, it is understandable that quality as discipline is practically applicable in every professional activity such as primary production, processing, services, and education; thus, one can say that quality is a horizontal discipline.

The most common tool to independently evaluate quality is conformity assessment in its various forms. Conformity assessment is defined (International Organization for

Responsible editor: Philippe Garrigues

Ioannis Papadakis

papadakis@iqc.gr

Fragoulis D. Krokos

fragoulis@rocketmail.com

Christos Trapalis

christrapalis@yahoo.gr

1 School of Science and Technology, Hellenic Open University, Patras GR 263 35, Greece

2 Hellenic Organization for Standardization, National Quality Infrastructure System, Peristeri GR 121 33, Greece

3 Hellenic Accreditation System, National Quality Infrastructure System, Kallithea GR 176 76, Greece
Standardization 2004a) as "demonstration that specified requirements relating to a product, process, system, person or body are fulfilled." Conformity assessment is governed and organized in a pyramidal structure. This quality infrastructure system and its individual elements such as accreditation and certification are described in details.

Moreover, this paper describes how analytical chemistry data are used in order accreditation and certification to fulfill their conformity assessment role. Specific examples are presented from environmental and food sectors. In this way, the usefulness of analytical chemistry to quality is demonstrated.

\section{Quality infrastructure system}

The pyramidal quality infrastructure system is graphically presented in Fig. 1.

On the top of the pyramid system, as the main pillar of conformity assessment, the key role is played by accreditation. However, the whole system would not be able to function without the vital contribution of standardization, metrology, and legislation. The various accredited activities are placed on the second level of the pyramid. These activities are the "heart" of conformity assessment" which is used by the "industry" and various "markets" in order to improve the "quality" of their products and services. In order to present them more efficiently, these activities are grouped according to the relevant accreditation standard. Within these accredited activities, certification activities are placed. The consumers, who benefit through improved quality from the increased value and confidence for the products and services that they are using, are placed at the bottom of the pyramid.

The specific elements of the abovementioned quality infrastructure system are presented in detail below together with their connection with analytical chemistry data. 


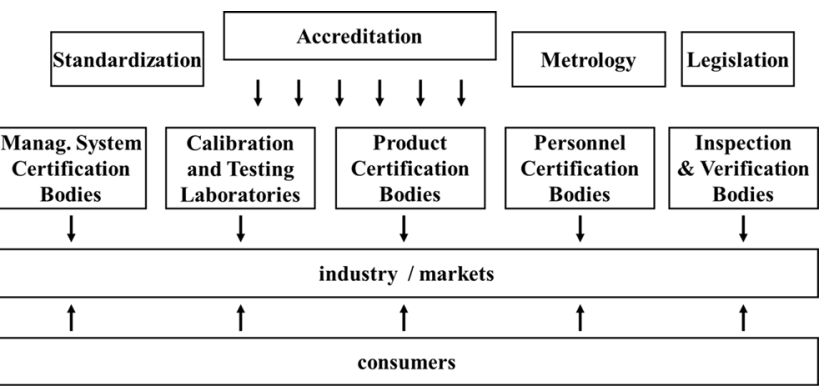

Fig. 1 Quality infrastructure system

\section{Standardization}

Standardization, according to ISO/IEC Guide 2 (International Organization for Standardization 2004b), is defined as the "activity of establishing, with regard to actual or potential problems, provisions for common and repeated use, aimed at the achievement of the optimum degree of order in a given context." It is actually the process of formulating, issuing, and implementing technical standards. This is a very important activity for the quality infrastructure system since all the conformity assessment activities that are performed for the proper functioning of the system require the appropriate standards which are produced by standards organizations and/or bodies.
Standardization is organized in three levels (graphically presented in Fig. 2), namely international (e.g., International Organization for Standardization), regional (e.g. European Committee for Standardization) and national (e.g., BSI in UK, DIN in Germany and NQIS/ELOT in Greece).

Analytical chemistry interacts with standardization both in terms of providing data to set up limits in specifications standards or to validate measurement standards (e.g., precision data) and in terms of implementing standardized measurement methods to provide reliable and acceptable data.

\section{Metrology}

According to the International Vocabulary of Metrology VIM (BIPM - JCGM 2012) Metrology is defined as the "science of measurement and its application." Metrology includes all theoretical and practical aspects of measurement, whatever the measurement uncertainty and field of application.

Metrology is providing to the quality infrastructure system the appropriate measurement support both in terms of infrastructure (i.e., measurement system, units, measurement standards, equipment etc.) and in terms of scientific background (i.e., development of measurement methods, providing measurement traceability, information in measurement uncertainty etc.) (Quevauviller et al. 1999; Rodrigues Filho and Gonçalves 2015).
Fig. 2 Presentation of different levels of organization of standardization, accreditation, and metrology

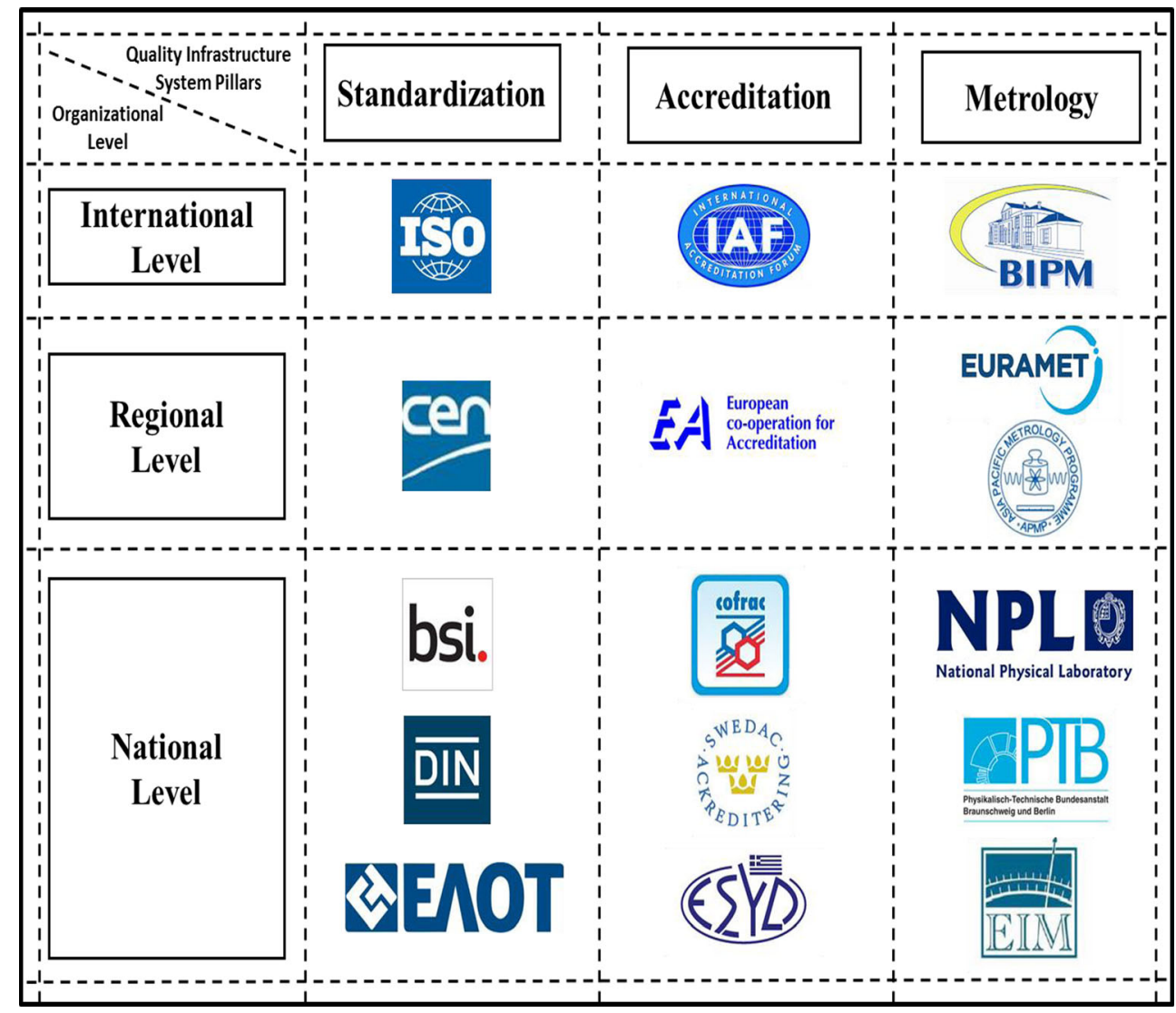


Metrology is also organized in various levels (graphically presented in Fig. 2), with International Bureau of Weights and Measures (BIPM) on the top international level and regional (e.g., EURAMET for Europe and APMP for Asia-Pacific) and national organizations (e.g., NPL for UK, PTB for Germany and NQIS/EIM in Greece) in the lower levels.

Analytical chemistry and metrology are inherently related. In fact, a dedicated sub-sector named chemical metrology exists within metrology, tackling metrological issues related to chemistry.

\section{Legislation}

Legislation is an important structural feature of modern organized societies. Legislation is generally defined as "a law or set of laws suggested by a government and made official by a parliament."

Legislation supports the quality infrastructure system providing the appropriate regulatory framework for the function of the system. This framework includes decision on and requirements for responsibilities of stakeholders, adoption, and enforcement of laws and standards and provision of appropriate relevant resources.

Analytical chemistry does not heavily interact with legislation. However, similarly with standardization in some specific cases, analytical chemistry data are used in order to set up limits (e.g., upper or lower levels) for specific law enforcement documents. Furthermore, legislative documents, as for example Commission Regulation (EU) no 589/2014 can specify quality requirements to be met by analytical procedures (European Commission 2014).

\section{Accreditation}

Accreditation is the main pillar of conformity assessment and the quality infrastructure system. Accreditation is defined (International Organization for Standardization 2004a) as the "third-party attestation related to a conformity assessment body conveying formal demonstration of its competence to carry out specific conformity assessment tasks." Accreditation is the demonstration of technical competence and impartiality of a (calibration or testing) laboratory or conformity assessment (certification or inspection) body.

Accreditation is also organized in a pyramidal system (graphically presented in Fig. 2), with international (e.g., International Accreditation Forum), regional (e.g., European Accreditation for Europe), and national organizations (e.g., Cofrac in France, SWEDAC in Sweden and NQIS/ESYD in Greece) on the relevant levels. The recognition of accredited certificates within each level is managed through Mutual Recognition Arrangements (MRA).

Accredited services are grouped according to the relevant accreditation standard, which also relates to the nature of the relevant sector. Five main groups are presented and discussed in this paper:

- Management system certification bodies,

- Calibration and testing laboratories,

- Product certification bodies,

- Personnel certification bodies,

- Inspection and verification bodies.

\section{Management system certification bodies}

Certification is defined (International Organization for Standardization 2014) as "a third-party issue of a statement, based on a decision following review, that fulfillment of specified requirements related to products, processes, systems or persons has been demonstrated." In the case of conformity assessment, this confirmation is provided by some form of external review, assessment, or audit. Management system certification bodies are certifying according to management system standards. The certification bodies are accredited according to ISO/IEC 17021-1 (International Organization for Standardization 2015e) in order to demonstrate their technical competence.

The management system certification is performed according to relevant standards. The most famous, well known, and mostly used management system standard ISO 9001 (International Organization for Standardization 2015d; Marimon et al. 2010; Franceschini et al. 2010; Llach et al. 2011) which describes requirements for a Quality Management System (QMS). Other commonly used management system standards are ISO 22000 (International Organization for Standardization 2005; Teixeira and Sampaio 2013; Escanciano and Santos-Vijande 2014) which describes requirements for a Food Safety Management System (FSMS) and ISO 14001 (International Organization for Standardization 2015a; Heras-Saizarbitoria et al. 2015, 2016; To and Lee 2014; Marimon et al. 2011) which describes requirements for an Environmental Management System (EMS).

Analytical chemistry data are often used in order to assess conformity in the framework of management systems certifications, as confirmed by the examples presented in the "Case studies" section originating from food safety and environment sectors.

\section{Calibration and testing laboratories}

Calibration and testing laboratories provide important services for the industry/market and the consumers. They practically disseminate the knowledge and infrastructure of metrology from the top of the quality infrastructure system to the bottom. Their services are used either directly from the consumer (e.g., 
a blood test) or by the industry (e.g., chemical analysis of water as production verification) or as part of the conformity assessment activities (e.g., laboratory documentation of foodstuff ingredients as fulfillment of FSMS requirements).

The calibration and testing laboratories in order to demonstrate that they perform their activities in an impartial, independent, and technically adequate way they are accredited according to ISO/IEC 17025 (International Organization for Standardization 2005).

The interaction with analytical chemistry, especially for the testing laboratories is quite high and a large number of such laboratories are solely chemical laboratories.

\section{Product certification bodies}

As mentioned in ISO/IEC 17065 (International Organization for Standardization 2012c), certification of products is a means of providing assurance that they comply with specified requirements in standards and other normative documents. Some product certification schemes may include initial testing or inspection and assessment of its suppliers' quality management systems, followed by surveillance that takes into account the quality management system and the testing or inspection of samples from the production and the open market. Other schemes rely on initial testing and surveillance testing, while still others comprise type testing only (Ticona and Frota 2008). Product certification bodies are accredited according to the ISO/IEC 17065 standard.

Analytical chemistry data are often used in order to assess conformity in the framework of product certifications, as confirmed by the example presented in the "Case studies" section originating from food safety sector.

\section{Bodies operating certification of persons}

As mentioned in ISO/IEC 17024 (International Organization for Standardization 2012b), certification for persons is one means of providing assurance that the certified person meets specified competence requirements and other requirements related to specific occupational or skilled categories of persons (Lengnick-Hall and Aguinis 2012). In contrast to other types of conformity assessment bodies, such as management system certification bodies, one of the characteristic functions of the certification body for persons is to conduct an examination, which uses objective criteria to measure competence and scoring. Bodies operating certification of persons are accredited according to ISO/IEC 17024 standard. Requirements and criteria against which a person can be certified can be described in standards. For example, ISO 9712 (International Organization for Standardization 2012d) provides a means of evaluating and documenting the competence of personnel whose duties require the appropriate theoretical and practical knowledge of the non-destructive tests they perform, specify, supervise, monitor, or evaluate.

This kind of certification is mentioned in this paper since it is distinctive section of the quality infrastructure system; however, there is no clear interaction with analytical chemistry apart from circumstantial connection when the certification scheme is related to chemistry.

\section{Inspection and verification bodies}

According to ISO/IEC 17020 (International Organization for Standardization 2012a), an inspection body is "a body that performs examination of a product, process, service, or installation or their design and determination of its conformity with specific requirements or, on the basis of professional judgment, with general requirements."

Inspection bodies are accredited according to ISO/IEC 17020 standard, and their services are quite important for various sectors, as a distinctive activity of conformity assessment.

Verification body is a body that performs verifications of GHG assertions in accordance with ISO 14064-3 (International Organization for Standardization 2006) and ISO 14065 (International Organization for Standardization 2013) standard. Verification is a systematic, independent, and documented process for the evaluation of a GHG assertion against agreed verification criteria. Until recently, they were also accredited according EN 45011; however recently new, more scope specific, accreditation standards were developed and thus verification bodies are accredited according to various standards depending on the type of verification. Example is the ISO 14065 standard which specifies principles and requirements for bodies that undertake validation or verification of greenhouse gas (GHG) assertions.

Analytical chemistry data are often used in order to assess conformity in the framework of inspection and verification, as confirmed by the examples presented in the "Case studies" section.

\section{Case studies}

\section{Management system certification bodies}

Examples of the application of analytical chemistry related to management system certification bodies conformity assessment is the use of analytical chemistry data for the certification of FSMS and EMS.

As far as FSMS is concerned, according to ISO annual survey on certifications to management system standards (International Organization for Standardization 2015f), ISO 22000 FSMS certifications continue to show a substantial increase on a yearly base. For 2014, the total number of certificates reported worldwide broke the 30.000 threshold 
reaching the number of 30.500 . ISO 22000 specifies requirements for a food safety management system where an organization in the food chain needs to demonstrate its ability to control food safety hazards in order to ensure that food is safe at the time of human consumption. One of these requirements provides that the acceptable level of the food safety hazard in the end product shall be determined and met, taking into account established statutory and regulatory requirements. For chemical contaminants (Maggioni et al. 2009) such as mycotoxins, polycyclic aromatic hydrocarbons (PAHs), dioxins and PCBs, acceptable levels, in terms of maximum levels, are set in EC Regulation 1881/2006 (European Commission 2006). In order for organizations to demonstrate that hazard levels are within identified acceptable levels, they have to rely on the results of chemical analyses. Furthermore, certification bodies providing certification of FSMS should also evaluate the analytical results in terms of validity and reliability (Mensah and Julien 2011). Validity and reliability of analytical results strongly depend on the technical competency of the laboratory performing the analysis. As already mentioned, accreditation of a laboratory to ISO/IEC 17025 provides a formal recognition of such competency. It is worth mentioning that one of the key factors that determine the correctness and reliability of the analysis performed by a laboratory is the analytical method used. ISO/IEC 17025 specifically mentions that laboratories implementing the standard shall preferably use methods published in international, regional or national standards. For example, EN 16619:2015 (European Committee for Standardization 2015) specifies a method for the determination of 4 (benz[a]anthracene, benzo[a]pyrene, benzo[b]fluoranthene and chrysene) of the $16 \mathrm{EU}$ priority polycyclic aromatic hydrocarbons (PAHs), identified as target PAHs and can be utilized by a laboratory performing analysis for the levels of these contaminants in foodstuff.

For the EMS certification, the ISO 14001 standard (Environmental Management Systems-Requirements with guidance for use) specifies the requirements for an environmental management system that an organization can implement in order to enchase its environmental performance.

The ISO 14001 standard requires the organization to determine the environmental aspects of its activities, products, and services that it can control and those that it can influence, and their associated environmental impacts, considering a life cycle perspective (ISO $14001 \S 6.1 .2$ Environmental aspects). Moreover, the standard requires the organization to monitor, measure, analyze, and evaluate its environmental performance (ISO $14001 \S$ 9.1 Monitoring, measurement, analysis, and evaluation).

Practically, the organization shall monitor and measure, in a stable and continuing basis, the key characteristics of its operations that have environmental impact. Each kind of impact should be monitored by analyzing relating data (e.g., air and soil releases to water and land) after an appropriate sampling procedure.
There is a direct relationship between analytical chemistry and EMS conformity assessment activities, since analytical chemistry provides the means to produce data and information that can be used by an organization in order to demonstrate compliance with the "monitoring, measurement, analysis and evaluation" requirement of the standard.

It is clear from the abovementioned examples that analytical chemistry is having a vital role for this type of conformity assessment.

\section{Product certification bodies}

A case study of the application of analytical chemistry related to product certification bodies' conformity assessment is the use of analytical chemistry for certification of organic products (Dabbert et al. 2014).

Council Regulation (EC) No 834/2007 (European Council 2007) and Commission Regulation (EC) No 889/2008 (European Commission 2008) are laying down detailed rules for organic production, labeling, and control of organic products. In the framework of these regulations, a very welldefined control system that ensures proper implementation of their provisions is set. Competent authorities of member states that have the overall responsibility for the control system may delegate, under certain conditions, specific control tasks, such as inspection and certification to one or more certification bodies (Zorn et al. 2012) (in the framework of the Regulations they are referred as "control bodies"). Recognizing the need that the authorized certification body has the competence to perform the tasks and that it is impartial and free from any conflict of interest as regards the exercise of the tasks delegated to it, the legislator has set the requirement that the certification body shall be accredited to ISO standards for product certification systems (eg. ISO/IEC 17065). One of the tasks delegated is that certification bodies, based on a riskbased sampling strategy, should conduct sampling and laboratory analysis (e.g., for GMO or pesticide residues). Furthermore, certification bodies providing organic product certification should also evaluate the analytical results in terms of validity and reliability. As in the case for FSMS, accreditation of a laboratory to ISO/IEC 17025 provides a formal recognition of its competence to provide valid and reliable results.

Once again, it is practically impossible to assess conformity without the involvement of analytical chemistry and evaluation of analytical chemistry data.

\section{Inspection and verification bodies}

An example of the application of analytical chemistry related to inspection bodies' conformity assessment is the use of methods of analytical chemistry for the vehicle technical control (or inspection). 
Vehicle technical control is being implemented around the world by governmental or private sector organizations, usually regulated by accreditation according to the ISO 17020 standard. In order to perform their inspection activities, the accredited organizations (inspection bodies) shall take into account the national legislation for vehicles and GHG emissions.

In general, inspection bodies performing inspections of road vehicles carry out these inspections on behalf of public authorities, according to prescribed laws, regulations, standards, directives or specifications, with the objective of certifying the conformity of the inspected vehicles with the requirements of these provisions.

Within EU common rules for vehicle inspection are established, resulting to a set of EU Directives, such as the European Directive 2014/45 (European Council 2014a) on periodic roadworthiness tests for motor vehicles and their trailers, the European Directive 2014/47 (European Council 2014b) on the technical roadside inspection of the roadworthiness of commercial vehicles circulating in the Union and repealing European Directive 2000/30/EC (European Council 2000).

Specific relation of the abovementioned with analytical chemistry exists in the framework of inspections of the gaseous emissions related with vehicle engines and the relevant exhaust emissions control equipment. Such conformity assessment activities cannot be performed properly without the valuable contribution of analytical chemistry.

A case study of the application of analytical chemistry related to verification bodies' conformity assessment is the use of methods of analytical chemistry for the verification of greenhouse gas emissions (GHG emissions).

In particular based on the European Directive 2003/87 (European Council 2003) and pursuant to EU Regulation 601/2012 (European Commission 2012), which is included in the mandatory sector, take place a reference to installations (operators and aircraft operators), who are obliged to monitor and verify greenhouse gas emissions among other means by the use of Continuous Emissions Measurement Systems (CEMS), such as online gas chromatographs or extractive or non- extractive gas analyzers.

In addition, the regulation refers special requirements for sampling, frequency of specific measurements, and the usage of specialized laboratories for the analyzing relating to emissions of greenhouse gasses.

Depending on the case, the measurements shall be carried out applying methods based on EN 14181 (European Committee for Standardization 2014) Stationary source emissions-Quality assurance of automated measuring systems, EN 15259 (European Committee for Standardization 2007) Air quality - Measurement of stationary source emissionsRequirements for measurement sections and sites and for the measurement objective, plan and report, and other corresponding EN standards.
Where such standards are not available, the methods shall be based on suitable ISO standards, standards published by the Commission or national standards. Where no applicable published standards exist, suitable draft standards, industry best practice guidelines or other scientifically proven methodologies shall be used, limiting sampling and measurement bias.

The conclusion drawn from the above case demonstrates the importance of the application of analytical chemistry and its methods for the verification of the emission of greenhouse gasses.

\section{Discussion and conclusions}

The relationship of analytical chemistry with standards has been discussed by other scientists (Valcarcel and Lucena 2013). In that analysis, it was mainly discussed the influence of the standards to the analytical chemistry and secondarily the opposite interaction.

In this paper, the interaction is documented in a broader sense, mainly in view of the role of the analytical chemistry data in terms of the quality infrastructure system operation, namely the conformity assessment activities, which are commonly known as accreditation and certification activities.

As part of their quality infrastructure, all economies need access to credible conformity assessment services. One of the key functions of conformity assessment is to provide confidence that products, processes, services, commodities, and personnel meet required specifications. The case studies presented in paragraph 3, document that in many cases, confidence rely on the use of analytical chemistry data. Taking into account this documentation, the quality infrastructure system graphical presentation of Fig. 1 is altered to the graphical presentation of Fig. 3 where the elements of the quality infrastructure system that are interacting with analytical chemistry are painted with red color.

It is clear that the role of analytical chemistry is dominant for the function of the quality infrastructure system. These activities are vital for the proper function of the industry/ markets and support the end user which is usually the

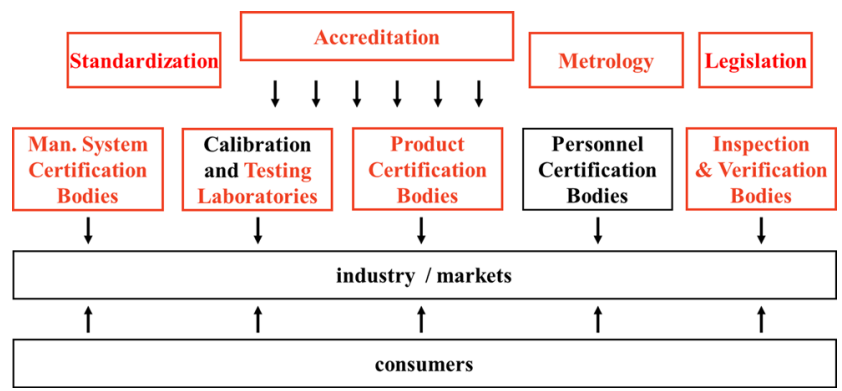

Fig. 3 Quality infrastructure system with indication of use of analytical chemistry data 
consumer. Consumers benefit from conformity assessment because it provides them with a basis for selecting products or services. On the other hand, manufacturers and service providers need to make sure that their products and services meet their declared specifications and deliver on customer expectations.

The extend of the interaction of analytical chemistry with conformity assessment activities coupled with the importance of the quality infrastructure system for industry and market function stress the need for reliable analytical chemistry data. Without impartial, reliable, and technically adequate chemical measurements, it would be practically impossible for the quality infrastructure system to function properly.

\section{References}

BIPM Joint Committee for Guides in Metrology (2012) International vocabulary of metrology - Basic and general concepts and associated terms (VIM), 3rd edn. Sèvres, France

Dabbert S, Lippert C, Zorn A (2014) Introduction to the special section on organic certification systems: policy issues and research topics. Food Policy 49:425-428

Escanciano C, Santos-Vijande ML (2014) Reasons and constraints to implementing an ISO 22000 food safety, management system: evidence from Spain. Food Control 40:50-57

European Council (2000) European Directive 2000/30/EC of the European Parliament and of the Council of 6 June 2000 on the technical roadside inspection of the roadworthiness of commercial vehicles circulating in the Community, Brussels, Belgium

European Council (2003) European Directive 2003/87/EC of the European Parliament and of the Council of 13 October 2003 establishing a scheme for greenhouse gas emission allowance trading within the Community and amending Council Directive 96/61/EC, Brussels, Belgium

European Council (2007) Council Regulation (EC) No 834/2007 of 28 June 2007 on organic production and labelling of organic products and repealing Regulation (EEC) No 2092/91, Brussels, Belgium

European Council (2014a) European Directive 2014/45 of the European Parliament and of the Council of 3 April 2014 on periodic roadworthiness tests for motor vehicles and their trailers and repealing Directive 2009/40/EC, Brussels, Belgium

European Council (2014b) European Directive 2014/47 of the European Parliament and of the council of 3 April 2014 on the technical roadside inspection of the roadworthiness of commercial vehicles circulating in the Union and repealing Directive 2000/30/EC, Brussels, Belgium

European Commission (2006) Commission Regulation (EC) No 1881/ 2006 of 19 December 2006 setting maximum levels for certain contaminants in foodstuffs, Brussels, Belgium

European Commission (2008) Commission Regulation (EC) No 889/ 2008 of 5 September 2008 laying down detailed rules for the implementation of Council Regulation (EC) No 834/2007 on organic production and labelling of organic products with regard to organic production, labelling and control, Brussels Belgium

European Commission (2012) Commission Regulation (EU) No 601/ 2012 of 21 June 2012 on the monitoring and reporting of greenhouse gas emissions, Brussels, Belgium

European Commission (2014) Commission Regulation (EU) No 589/ 2014 of 2 June 2014 laying down methods of sampling and analysis for the control of levels of dioxins, dioxin-like PCBs and nondioxin-like PCBs in certain foodstuffs and repealing Regulation (EU) No 252/2012, Brussels, Belgium

European Committee for Standardization (2007) EN 15259:2007 Air quality - Measurement of stationary source emissions Requirements for measurement sections and sites and for the measurement objective, plan and report, and other corresponding EN standards, Brussels, Belgium

European Committee for Standardization (2014) EN 14181:2014 Stationary source emissions - Quality assurance of automated measuring systems, Brussels Belgium

European Committee for Standardization (2015) EN 16619:2015 Food analysis - Determination of benzo[a]pyrene, benz[a]anthracene, chrysene and benzo[b]fluoranthene in foodstuffs by gas chromatography mass spectrometry (GC-MS), Brussels, Belgium

Franceschini F, Galetto M, Maisano D, Mastrogiacomo L (2010) Clustering of European countries based on ISO 9000 certification diffusion. Int J Qual Reliab Manag 27(5):558-575

Heras-Saizarbitoria I, Arana G, Boiral O (2015) Exploring the dissemination of environmental certifications in high and low polluting industries. J Clean Prod 89:50-58

Heras-Saizarbitoria I, Boiral O, Arana G (2016) Renewing environmental certification in times of crisis. J Clean Prod 115:214-223

International Organization for Standardization (2004a) ISO/IEC 17000: 2004 Conformity assessment - Vocabulary and general principles, Geneva, Switzerland

International Organization for Standardization (2004b) ISO/IEC Guide 2: 2004 Standardization and related activities - General vocabulary, Geneva, Switzerland

International Organization for Standardization (2005) ISO/IEC 17025: 2005 General requirements for the competence of testing and calibration laboratories, Geneva, Switzerland

International Organization for Standardization (2006) ISO 14064-3:2006 Greenhouse gases - Part 3: Specification with guidance for the validation and verification of greenhouse gas assertions, Geneva, Switzerland

International Organization for Standardization (2012a) ISO/IEC 17020: 2012 Conformity assessment - Requirements for the operation of various types of bodies performing inspection, Geneva, Switzerland

International Organization for Standardization (2012b) ISO/IEC 17024: 2012 Conformity assessment - General requirements for bodies operating certification of persons, Geneva, Switzerland

International Organization for Standardization (2012c) ISO/IEC 17065: 2012 Conformity assessment - Requirements for bodies certifying products, processes and services, Geneva, Switzerland

International Organization for Standardization (2012d) ISO 9712:2012 Non-destructive testing - Qualification and certification of NDT personnel, Geneva, Switzerland

International Organization for Standardization (2013) ISO 14065:2013 Greenhouse gases - Requirements for greenhouse gas validation and verification bodies for use in accreditation or other forms of recognition, Geneva, Switzerland

International Organization for Standardization (2015a) ISO 14001:2015 Environmental management systems - Requirements with guidance for use, Geneva, Switzerland

International Organization for Standardization (2015b) ISO 22000:2005 Food safety management systems - Requirements for any organization in the food chain, Geneva, Switzerland

International Organization for Standardization (2015c) ISO 9000:2015 Quality management systems - Fundamentals and vocabulary, Geneva, Switzerland

International Organization for Standardization (2015d) ISO 9001:2015 Quality management systems - Requirements, Geneva, Switzerland International Organization for Standardization (2015e) ISO/IEC 17021$1: 2015$, Conformity assessment - Requirements for bodies 
providing audit and certification of management systems - Part 1: Requirements, Geneva, Switzerland

International Organization for Standardization (2015f) ISO survey, http:// www.iso.org/iso/iso-survey, Geneva, Switzerland, Accessed 31 Jan 2016

Lengnick-Hall ML, Aguinis H (2012) What is the value of human resource certification? A multi-level framework for research. Hum Resour Manag Rev 22:246-257

Llach J, Marimon F, Bernardo M (2011) ISO 9001 diffusion analysis according to activity sectors. Ind Manag Data Syst 111(2):298-316

Maggioni S, Benfenati E, Colosio C, Moretto A, Roots O, Tasiopoulou S, Visentin S (2009) Food contamination control in European new member states and associated candidate countries: data collected within the SAFEFOODNET project. J Environ Sci Health, Part B 44(4):407-414

Marimon F, Casadesús M, Heras I (2010) Certification intensity level of the leading nations in ISO 9000 and ISO 14000 standards. Int J Qual Reliab Manag 27(9):1002-1020

Marimon F, Llach J, Bernardo M (2011) Comparative analysis of diffusion of the ISO 14001 standard by sector of activity. J Clean Prod 19:1734-1744
Mensah LD, Julien D (2011) Implementation of food safety management systems in the UK. Food Control 22:1216-1225

Quevauviller P, de Castro CN, Morabito R, Válcarcel M, Voulgaropoulos A (1999) Needs for improvement of the measurement infrastructure in Europe. Trends Anal Chem 18:650-655

Rodrigues Filho BA, Gonçalves RF (2015) Legal metrology, the economy and society: a systematic literature review. Measurement 69:155-163

Teixeira S, Sampaio P (2013) Food safety management system implementation and certification: survey results. Total Qual Manag Bus Excell 24(3-4):275-293

Ticona JM, Frota MN (2008) Assessment of the economic impact of product certification: a significant area of application of measurement. Measurement 41:88-104

To WM, Lee PKC (2014) Diffusion of ISO 14001 environmental management system: global, regional and country-level analyses. J Clean Prod 66:489-498

Valcarcel M, Lucena R (2013) Synergistic relationships between analytical chemistry and written standards. Anal Chim Acta 788:1-7

Zorn A, Lippert C, Dabbert S (2012) Supervising a system of approved private control bodies for certification: the case of organic farming in Germany. Food Control 25:525-532 